\title{
The glutathione S-transferase (PxGST2L) may contribute to the detoxification metabolism of chlorantraniliprole in Plutella xylostella(L.)
}

\author{
Fei Yin $\mathbb{D}^{1,2} \cdot$ Qingsheng $\operatorname{Lin}^{1,2} \cdot$ Xiaoxiang Wang ${ }^{1,2} \cdot{\text { Zhenyu } \mathrm{Li}^{1,2} \cdot \text { Xia Feng }^{1,2} \cdot \text { Muhammad Zeeshan Shabbir }}^{1}$
}

Accepted: 25 May 2021 / Published online: 10 June 2021

(c) The Author(s) 2021

\begin{abstract}
The diamondback moth (Plutella xylostella L.), is an economic pest of cruciferous plants worldwide, which causes great economic loss to cruciferous plants production. However, the pest has developed resistance to insecticides. One of such insecticides is chlorantraniliprole. The study of the mechanisms underlying resistance is key for the effective management of resistance. In this study, a comparative proteomics approach was used to isolate and identify various proteins that differed between chlorantraniliprole-susceptible and -resistant strains of $P$. xylostella. Eleven proteins were significantly different and were successfully identified by MALDI-TOF-MS. Metabolism-related proteins accounted for the highest proportion among the eleven different proteins. The function of the PxGST2L protein was validated by RNAi. Knockdown of PxGST2L reduced the GST activity and increased the toxicity of chlorantraniliprole to the diamondback moth. The resistance ratio of diamondback moth to chlorantraniliprole was reduced from 1029 to 505. The results indicated that PxGST2L is partly responsible for chlorantraniliprole insecticide resistance in DBM. Our finding contributes to the understanding of the mechanism underlying resistance to chlorantraniliprole in the DBM, to develop effective resistance management tactics.
\end{abstract}

Keywords Plutella xylostella (L.) $\cdot$ Chlorantraniliprole $\cdot$ Insecticide resistance $\cdot 2$-DE $\cdot$ RNAi

\section{Introduction}

The diamondback moth (DBM), Plutella xylostella (L.) (Lepidoptera: Brassicidae) is a global pest of Brassica plants (Li et al. 2016; Sarfraz et al. 2006; Takeda et al. 2006). DBM develops resistance to insecticides very rapidly due to its physiological and biochemical characteristics. At present, DBM has developed resistance to all major classes of insecticides(Arruda et al. 2020; Charleston et al. 2005; Jing et al. 2021; Li et al. 2020; Pu et al. 2010; Wang et al. 2019; Zhao et al. 2006). The lack of effective insecticides makes it difficult to prevent and control DBM. Approximately US

Qingsheng Lin

linqs8066@126.com

1 Institute of Plant Protection, Guangdong Academy of Agricultural Sciences, Guangzhou, P.R. China

2 Guangdong Provincial Key Laboratory of High Technology for Plant Protection, Guangzhou, P.R. China
\$4-5 billion is spent globally every year to manage DBM (Furlong et al. 2013).

Chlorantraniliprole was reported to be the most active compound against lepidopteran pests in 2009. It has a novel mode of action that acts on the ryanodine receptor (RyR) (Cordova et al. 2006; Lahm et al. 2005, 2007). Due to its low mammalian toxicity, high activity and unique mechanism of action, the pesticide has been used widely. It has been registered for use in more than 80 countries and ranked among the 5 top-selling insecticides worldwide in 2011. However, long-term use of chemical agent can increase the fitness cost and survival ability of pest, leading to a likely resurgence of this pest (Desneux et al. 2007). Likewise, Bradysia odoriphaga (Diptera: Apicymphaeidae) developed 76 and 43.32 fold resistance to clothianidin and chlorfenapyr insecticides after 10 generations of selection. The larvae and pupae survived longer and generation cycle increase in resistant strains (Gul et al. 2019; Ullah et al. 2020a). The clothianidin adversely affect the adult longevity and fecundity of progeny of Aphis gossypii Glover (Hemiptera: Aphididae) at low or sublethal concentrations (Ullah et al. 2019a). The cyantraniliprole-treated strains of 
Laodelphax straatellus (Fallen) (Hemiptera: Delphacidae) increased faster compared to control strain (Zhang et al. 2019). Acetamiprid and imidacloprid affect the vitellogenin gene $(\mathrm{Vg})$ expression in melon aphid, A. gossypii (Ullah et al. 2019b, c). Long-term use of chlorantraniliprole affect the net reproductive rate, mean generation time and doubling time of Harmonia axyridis (Coleoptera: Coccinellidae), Trichogramma brassicae (Hymenoptera: Hypteridae) and Apis mellifera (L.) (Hymenoptera: Apidae) (Oliveira et al. 2019; Parsaeyan et al. 2020; Williams 2020). The low contact toxicity of chlorantraniliprole affected the survival, development and predation ability of Coccinella septempunctata (Coleoptera: Coccinellidae) (He et al. 2019). After a long period of heavy use of chlorantraniliprole, resistance of DBM to chlorantraniliprole was reported in South China, Thailand, the Philippines and Brazil (Ribeiro et al. 2014; Wang et al. 2010; Wang and Wu 2012). In China, this resulted in an outbreak of the pest. About US $\$ 0.77$ billion is spent annually on the control of DBM and crop losses in China (Li et al. 2016).

The metabolic resistance, target-site resistance, penetration and behavioral resistance are primary resistance mechanisms in the target insects (Guedes et al. 2019; Ingham et al. 2018). Previously it was reported that cytochrome $\mathrm{P} 450$ monooxygenases (P450s) genes was involved in acetamiprid resistance in A. gossypii and chlorantraniliprole resistance in P. xylostella (L.) (Li et al. 2018; Ullah et al. 2020b). P450 gene regulate the insecticide resistance of mosquitoes through GPCR/Gos/AC/cAMP-PKA signaling pathways ( $\mathrm{Li}$ and $\mathrm{Liu}$ 2017, 2019). Modified acetylcholinesterase (AChE) phenotype (MACE) caused by a mutation in the ACHE gene (ace2) is strongly involved in the resistance of Myzus persicae (Sulzer) (Homoptera: Aphididae) to pirimicarb (Liu et al. 2017). Most studies on the mechanisms underlying resistance in DBM have focused on genetic and physiological changes and have reported that mutation of RYR and detoxification metabolism as the two main causes (He et al. 2012; Li et al. 2020; Wang et al. 2020). Transport protein ABCC 2 participates in the resistance of DBM to avermectin and chlorfenapyr (Xu et al. 2019). The Pglycoprotein gene $p X A B C B 1$ is closely related to diamondback moth resistance to Cry1Ac toxin (Zhou et al. 2020). Over-expression of UDPglycosyltransferase gene $U G T 2 B 17$ and cytochrome P450 $C Y P 6 B G 1$ are reported to be involved in chlorantraniliprole resistance in P. xylostella (L.) (Li et al. 2018; Li et al. 2016). However, gene mutations and physiological changes are influenced by proteins. Proteomics is a powerful method for gaining insight into various physiological changes at the cellular level. It has been applied in numerous studies, including immunity, resistance mechanisms and pathology, etc. (Guo et al. 2014; Etebari et al. 2011). In this study, a comparative proteomic approach was used to identify resistance-related proteins. The different expressions of metabolism-related proteins were further validated. These results make an important contribution to better understand the mechanism underlying resistance to chlorantraniliprole in DBM.

\section{Materials and methods}

\section{Insects}

A susceptible P. xylostella strain (SS) was originally collected from vegetable fields (Guangdong Province, China) in 2002 and was reared separately in the laboratory without any insecticides exposure for fourteen years.

The pupae of chlorantraniliprole resistant DBM strain (RS) were collected from vegetable fields in Guangdong Province, China and the larva were reared on Brassica alboglabra L. H. Bailey in the laboratory. The laboratory conditions were maintained at $25 \pm 2{ }^{\circ} \mathrm{C}, 65 \pm 5 \%$ relative humidity (RH) and 16:8 h light: dark photoperiod.

\section{Leaf bioassay}

The leaf dip method was used in the bioassay. Cabbage leaf discs $(6.5 \mathrm{~cm}$ in diameter) were prepared using a hole punch. The leaves were soaked in the liquid for $10 \mathrm{sec}$ and then air dried $2 \mathrm{~h}$ at room temperature. The leaves were placed in a Petri dish with a diameter of $6.5^{\circ} \mathrm{C}$. Ten third-instars larvae of P.xylostella L. were transferred to each plastic Petri dish and kept at $25 \pm 2{ }^{\circ} \mathrm{C}, 65 \pm 5 \% \mathrm{RH}$ with a photoperiod of 16: $8(\mathrm{~L} ; \mathrm{D})$. There are four repetitions per treatment. Leaves treated with distilled water alone were used as control. After $48 \mathrm{~h}$, the mortality was examined. The larvae were considered to be dead when they do not respond by touching with small brush. Bioassays which showed mortality rates $>10 \%$ in the control were discarded, and the whole bioassay was repeated four times.

The data were analyzed with SPSS 19 software. The resistance ratios (RRs) were estimated at the LC 50 level as $\mathrm{RR}=\mathrm{LC} 50$ of testing strain/ LC 50 of susceptible strain.

\section{Protein extraction}

Twenty 3-instar larvae of each strain were ground thoroughly to fine powder using a mortar and pestle in liquid nitrogen. The method for total protein extraction followed the procedure described previously (Yin et al. 2017). The powder was resuspended in $1 \mathrm{~mL}$ of extraction buffer ( $40 \mathrm{mmol} / \mathrm{L}$ DTT and $10 \%$ TCA in acetone) for $1 \mathrm{~h}$ at $4{ }^{\circ} \mathrm{C}$., The samples were then centrifuged at $15,000 \mathrm{rpm}$ for $30 \mathrm{~min}$ at $4{ }^{\circ} \mathrm{C}$. The supernatant was discarded. The precipitate was 
Table 1 Primers used in the quantitative real-time RT-PCR analysis

\begin{tabular}{lll}
\hline Target gene & Primer name & Primer sequence $\left(5^{\prime}-3\right)^{\prime}$ \\
\hline Juvenile hormone diol kinase & $\mathrm{J}-\mathrm{F}$ & GGCACGAGGCAGCGACAACACAAGC \\
& $\mathrm{J}-\mathrm{R}$ & TGCCCGTCGTTGTTGGCGTCAG \\
Cu/Zn superoxide dismutase & CZ-F & GAGAGCATTGGGGGCGTCACTA \\
& CZ-R & GGCACCCTAACATTTATGCTGAT \\
Glutathione S-transferase 4 protein & G-F & CGAGTTCAAGCCCAAGACCA \\
(PxGST2L) & G-R & CCTTCTCATCTTCTTCGTAGTGGA \\
Triosephosphate isomerase & T-F & AGGATGTTGGGTCTGAGTGGGT \\
& T-R & TGATTTCATGGATTGTGTTCTTGTC \\
Imaginal disk growth factor & I-F & GTGCCCGCCATCATCAACTTCG \\
$\beta$-actin & I-R & GCGATGCCCACCACGATCTTAG \\
& A-F & TGGCACCACACCTTCTAC \\
& A-R & CATGATCTGGGTCATCTTCT \\
\hline
\end{tabular}

resuspended three times in 3 volumes of ice-cold acetone for $1 \mathrm{~h}$ at $-20^{\circ} \mathrm{C}$ followed by centrifugation at $12,000 \mathrm{rpm}$ for $10 \mathrm{~min}$. This procedure was repeated twice. The protein was resuspended in $500 \mu \mathrm{L}$ of lysis buffer $(2 \mathrm{~mol} / \mathrm{L}$ thiourea, $4 \%$ (v/v) CHAPS, 2\% (v/v) Bio-lyteampholytes (pH 3-10), $7 \mathrm{~mol} / \mathrm{L}$ urea and $40 \mathrm{mmol} / \mathrm{L} \mathrm{DTT}$ ) for $2 \mathrm{~h}$ at $4{ }^{\circ} \mathrm{C}$ followed by centrifugation at $15,000 \mathrm{rpm}$ for $30 \mathrm{~min}$. The supernatant was stored at $-80{ }^{\circ} \mathrm{C}$ and the total protein concentration was estimated according to the manufacturer's instructions using a Bradford protein assay kit (Generay, China) (Jin et al. 2010).

\section{Two dimensional gel electrophoresis (2-DE) and image analysis}

A total of $1 \mathrm{mg}$ protein was loaded on 17-cm Immobiline dry strips ( $\mathrm{pH} 3-10$, NL, Bio-Rad) with rehydration buffer $(2 \mathrm{~mol} / \mathrm{L}$ thiourea, $40 \mathrm{mmol} / \mathrm{L}$ DTT, $2 \%$ (v/v) CHAPS, $2 \%$ (v/v) Bio-lyteampholytes (pH 3-10), 7 mol/ $\mathrm{L}$ urea and $0.002 \%$ bromophenol blue). The gel strips were transferred to an Ettan IPG Phor system (Bio-Rad) after active rehydration for $16 \mathrm{~h}$. Isoelectric focusing was performed at $250 \mathrm{~V}$ for $3 \mathrm{~h}, 1000 \mathrm{~V}$ for $4 \mathrm{~h}, 10,000 \mathrm{~V}$ for $5 \mathrm{~h}$, and $10,000 \mathrm{~V}$ to reach $8000 \mathrm{Vhr}$ and held at $500 \mathrm{~V}$. Then, the strips were equilibrated in equilibration buffer containing $2 \%(\mathrm{w} / \mathrm{v}) \mathrm{SDS}, 1 \%(\mathrm{w} / \mathrm{v}) \mathrm{DTT}, 50 \mathrm{mmol} / \mathrm{L}$ Tris-HCl, $\mathrm{pH} 8.8,20 \%$ (v/v) glycerol, $6 \mathrm{~mol} / \mathrm{L}$ urea, $0.002 \%(\mathrm{w} / \mathrm{v})$ bromophenol blue and $1.5 \%(\mathrm{w} / \mathrm{v})$ iodoacetamide for $15 \mathrm{~min}$ at room temperature. The strips were then loaded onto $12 \%(\mathrm{w} / \mathrm{v})$ SDS-PAGE gels and sealed with $0.5 \%$ agarose. SDS-PAGE was performed at $80 \mathrm{~V}$ for $30 \mathrm{~min}$ followed by $200 \mathrm{~V}$ for $4.5 \mathrm{~h}$ on an Ettan DALT-6 separation unit (Bio-Rad).

When SDS-PAGE was completed, the gels were stained with Coomassie and scanned using a GS 800 scanner. The protein spots were analyzed using the PDQuest software
(Bio-Rad). Statistical analysis was performed with Student's $t$ test. $P$ values less than 0.05 were considered statistically significant. Only differentially expressed proteins ( $\geq 2.0$-fold or $\leq 0.5$-fold) were excised and subjected to subsequent identification by mass spectrometry (MS) (Bruker Daltonics, Germany).

\section{MALDI-TOF/TOF-MS/MS analysis}

The differentially expressed protein spots of interest were excised. The pieces were then processed by in-gel trypsin digestion and analyzed by MALDI-TOF-MS/MS (Bu et al. 2012). The MS/MS data were searched against the expressed sequence tag (EST) and NCBI protein databases using MASCOT search engine (Matrix Science, London, UK). MASCOT score over 50 was considered to be a positive hit. The molecular functions of identified proteins were classified by the GO database (http://amigo. geneontology.org/amigo/landing).

\section{Quantitative real-time PCR (RT-qPCR)}

To investigate the differentially expressed proteins, four proteins were selected for additional analysis. Actin served as the reference gene. Total RNA was extracted from third instar larvae of DBM using an EASYspin RNA rapid isolation kit for tissue/cells (Biomed, Beijing) according to the manufacturer's protocol. First strand cDNA was synthesized from $1 \mu \mathrm{g}$ of RNA using M-MLV reverse transcriptase (Takara Bio Inc, kusatsu, shiga, Japan). RT-qPCR was performed in triplicate in a Rotor-Gene thermal cycler (BioRad). Each $20 \mu \mathrm{l}$ reaction mixture contained $2 \mu \mathrm{l} 0.2 \mu \mathrm{M}$ each primer (Table 1), $10 \mu \mathrm{l} 2 \mathrm{X}$ All-in-One qPCR Mix, $2 \mu \mathrm{l}$ diluted cDNA and $4 \mu \mathrm{l}$ of $\mathrm{ddH}_{2} \mathrm{O}$. The relative gene expression level was calculated using the $2^{-\Delta \Delta C T}$ method (Lin et al. 2013). 
Table 2 Primers for dsRNA synthesis

\begin{tabular}{ll}
\hline Primer sequence & Primer name \\
\hline GCTGTAGACGGTTTCGTAGAC & dsPxGST2L-F \\
TCACAATGCCGGTGGTAAA & dsPxGST2L-R \\
GGATCCTAATACGACTCACTATAGGTCACAATGCCGGTGGTAAA & dsPxGST2L-T7F \\
GGATCCTAATACGACTCACTATAGGGCTGTAGACGGTTTCGTAGAC & dsPxGST2L-T7R \\
AAGGGCGAGGAGCTGTTCACCG & dsGFP-F \\
CAGCAGGACCATGTGATCGCGC & dsGFP-R \\
GGATCCTAATACGACTCACTATAGGAAGGGCGAGGAGCTGTTCACCG & dsGFP-T7F \\
GGATCCTAATACGACTCACTATAGGCAGCAGGACCATGTGATCGCGC & dsGFP-T7R \\
\hline
\end{tabular}

\begin{tabular}{llclcc}
\hline Control & $\begin{array}{l}\text { Regression } \\
\text { equation }\end{array}$ & LC50 $(\mathrm{mg} / \mathrm{L})$ & $\begin{array}{l}\text { 95\% confidence interval/ } \\
\mathrm{mg} \cdot \mathrm{L}-1\end{array}$ & $\mathrm{X}^{2}(\mathrm{df})^{\mathrm{a}}$ & $\mathrm{RR}^{\mathrm{b}}$ \\
\hline $\begin{array}{l}\text { Resistant population } \\
\text { Susceptible }\end{array}$ & $\mathrm{Y}=1.595-3.244$ & 108.01 & $80.11-165.61$ & $1.246(3)$ & 490.95 \\
population & $\mathrm{Y}=1.592 \mathrm{x}+$ & 0.22 & $0.13-0.36$ & $0.696(3)$ & - \\
\hline
\end{tabular}

${ }^{\mathrm{a}}$ Chi-square value (X2) and 180 degrees of freedom (df)

${ }^{b} \mathrm{RR}$ (resistance ratio) $=$ the resistant population LC50/ the susceptible population LC50

\section{Functional verification of glutathione S-transferase 4 protein (PXGST2L) by RNAi}

The dsRNA of PxGST2L genes were synthesized according to the instructions of the T7 RioMAXTM Express RNAi System. Primers are shown in Table 2. The dsRNA $(2 \mu \mathrm{g} /$ larva) was injected into 3rd instar larvae. The expression of the PxGST2L genes and the activity of glutathione Stransferase (GST) were evaluated $24 \mathrm{~h}$ after treatment following Chen's method (Chen and Zhang 2015). The toxicity of chlorantraniliprole to DBM was then tested using the leaf-dipping method $24 \mathrm{~h}$ after the dsRNA treatment (Guo et al. 2014). The tests were repeated three times, and 10 DBM were used for each replication. The control group was injected with green fluorescent protein dsRNA (dsGFP) (CK). Concentration-mortality data $\left(\mathrm{LC}_{50}\right)$ were analyzed using SPSS19 (Software, IBM). Resistance ratio (RR) was calculated by the formula, $\mathrm{RR}=$ the resistant population $\mathrm{LC}_{50} /$ the susceptible population $\mathrm{LC}_{50}$.

\section{Results}

\section{Toxicity of chlorantraniliprole against $P$. xylostella $L$}

The leaf dip bioassays showed that chlorantraniliprole was toxic to the susceptible and the resistant strains with $\mathrm{LC}_{50}$ value of 0.22 and $108.01 \mathrm{mg} \mathrm{L}^{-1}$. The resistant ratio is 490.95 (Table 3).

\section{2-DE analysis of differentially expressed proteins in the CS and CR of DBM}

The proteins were separated by 2-DE, and the gels were scanned and analyzed using the PDQuest software. Approximately 520 protein spots were detected in each gel. Twenty-two proteins were significantly different $(r \geq 2.00, p$ $<0.05$ ) in abundance (Fig. 1). Eleven proteins were successfully identified by MALDI-TOF-MS/MS. All mascot scores were over 60 . The expression levels of nine proteins (spots 1, 6, 7, 11, 13, 14, 15, 16 and 18) were upregulated and two proteins (spots 21 and 22) were downregulated in CR (Table 4). These proteins have important biological functions including metabolism-related, structural protein, chaperonin and diapause proteins. Metabolism-related proteins accounted for $45.45 \%$ among the 11 different proteins (Fig. 2).

\section{Differential gene expression at the mRNA and protein levels in CS and CR of DBM}

To investigate the mRNA expression of these proteins, four proteins (spots 6, 14, 16 and 18) were selected for additional analysis at the mRNA level using RT-qPCR. The results showed that $\mathrm{Cu} / \mathrm{Zn}$ superoxide dismutase, glutathione $\mathrm{S}$ transferase 4 protein, triosephosphate isomerase and imaginal disk growth factor, were significantly upregulated at the mRNA level (Fig. 3). The changes in the mRNA levels of these four proteins were consistent with the corresponding protein levels (Fig. 4). 
Fig. 1 2-DE Gel analysis of the protein expression of the DBM between CS and CR. A resistant strain; (B) susceptible strain. In IEF, a total of $1 \mathrm{mg}$ protein was separated on $17 \mathrm{~cm}, \mathrm{pH}$ 3-10 NL immobiline dry strips. SDS-PAGE was performed with $12 \%$ gels, and the protein spots were visualized using G250 staining. 22 proteins change significantly $(P<0.05$, fold $\geq 2.0$ ). 11 proteins were identified successfully
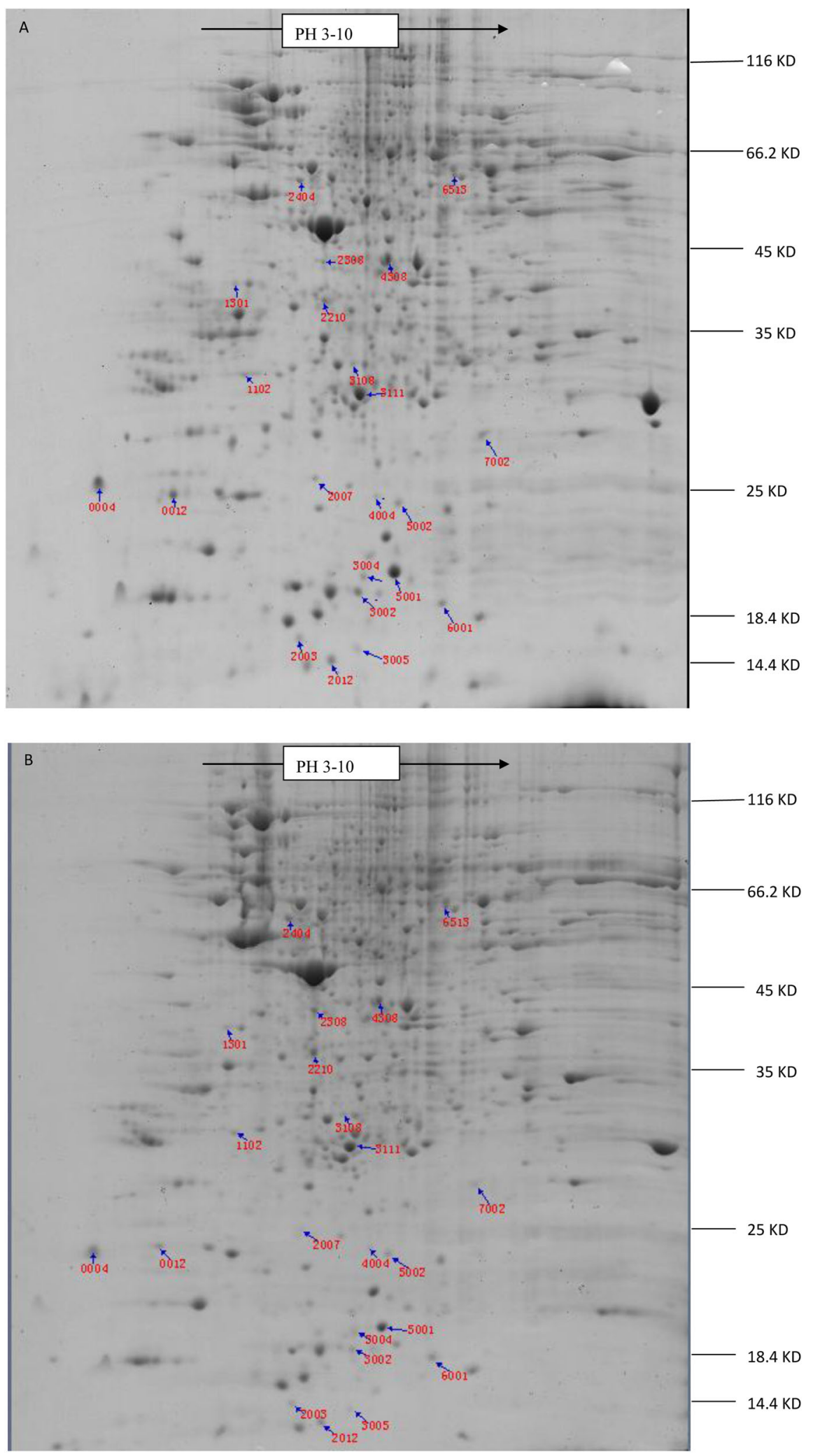
Table 4 MALDI-TOF/TOF MS identification of differentially expressed proteins of Plutella. Xylostellai n CS and CR

\begin{tabular}{|c|c|c|c|c|c|c|c|}
\hline Spot number & $\mathrm{SSP}^{\mathrm{a}}$ & Protein name & Accession number & Mascot score & Isoelectric point & Coverage rate $(\%)$ & Express effect ${ }^{\mathrm{b}}$ \\
\hline 1 & 0004 & Juvenile hormone diol kinase & gil49532884 & 208 & 4.5 & 24 & Up \\
\hline 6 & 3002 & $\mathrm{Cu} / \mathrm{Zn}$ superoxide dismutase & gil53148457 & 253 & 6.3 & 25 & Up \\
\hline 7 & 5001 & abnormal wing disc-like protein & gil330370526 & 169 & 9.5 & 19 & Up \\
\hline 11 & 4004 & diapause bioclock protein & gil357621212 & 59 & 6.3 & 7 & Up \\
\hline 13 & 7002 & peptidylprolyl isomerase B & gil357609162 & 67 & 8.9 & 6 & Up \\
\hline 14 & 3111 & glutathione S-transferase 4 & gil49532926 & 429 & 5.8 & 31 & Up \\
\hline 15 & 3108 & heat shock protein 1 & gil357614091 & 191 & 6.4 & 23 & Up \\
\hline 16 & 1102 & triosephosphate isomerase & gil440200451 & 201 & 4.7 & 25 & Up \\
\hline 18 & 6513 & imaginal disk growth factor & gil117970190 & 238 & 8.5 & 13 & Up \\
\hline 21 & 2210 & proteasome alpha 6 subunit & gil17737405 & 118 & 6.1 & 9 & Down \\
\hline 22 & 2404 & phosphoglycerate kinase & gil389614755 & 80 & 5.4 & 11 & Down \\
\hline
\end{tabular}

${ }^{\mathrm{a}} \mathrm{SSP}$ : protein number

${ }^{\mathrm{b}} \mathrm{Up}$ : up-regulated protein; down: down-regulated protein

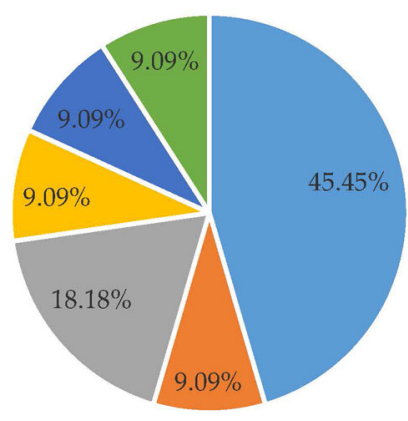

- Metabolism proteins

m growth factor

- diapause protein

m structural proteins

other

Fig. 2 Gene ontology (Go) categories of the different proteins identified from the P. xylostella in CS and CR. The annotations for the identified proteins were retrieved by searching against the GO database with their sequences. The molecular functions of identified proteins were classified according to their GO annotations

\section{Functional verification of the PXGST2L by RNAi}

To determine whether the highly expressed PxGST2L was capable of providing chlorantraniliprole resistance in the $\mathrm{CR}$, it was silenced by injection of PxGST2L dsRNA (dsPxGST2L) in DBM larvae. PxGST2L gene expression was significantly lower than the control (dsGFP) $24 \mathrm{~h}$ after injection of dsGST2L and dsGFP. This indicated that the relative expression of $P x G S T 2 L$ was significantly decreased by the dsRNA treatments ( $2 \mu \mathrm{g} /$ larva). The efficiency of the RNAi was $>76 \%$ (Fig. 5A). The activity of GSTs was significantly decreased (more than 60\%) (Fig 5B). Silencing of PxGST2L increased the toxicity of chlorantraniliprole to DBM. The resistance ratio of DBM to chlorantraniliprole was reduced from 1029 to 505 (Table 5).

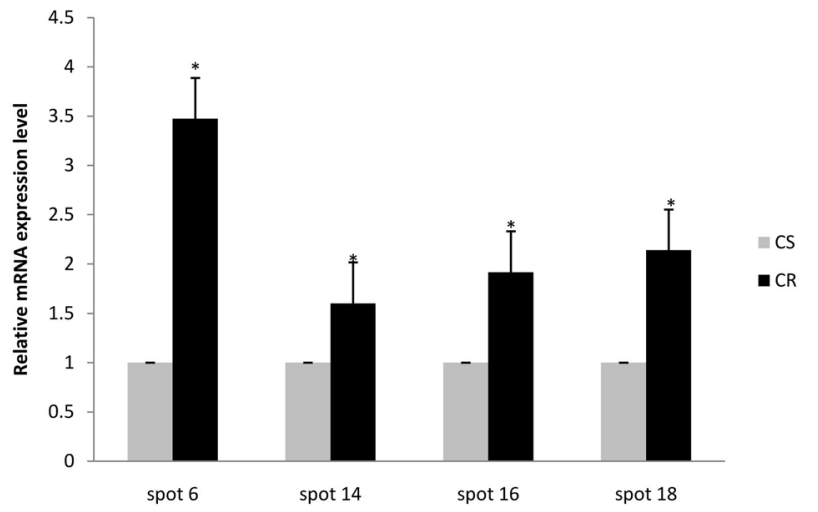

Fig. 3 Expression of four genes at the mRNA levels between the chlorantraniliprole-sensitive (SS) and resistant (RS) strains of $P$. xylostella. Spot 6: $\mathrm{Cu} / \mathrm{Zn}$ superoxide dismutase; Spot 14: glutathione S-transferase 4 protein; Spot 16: triosephosphate isomerase; Spot 18: imaginal disk growth factor. CS, susceptible $P$. xylostella strain; CR, chlorantraniliprole resistant DBM strain. The expression level of the protein and mRNA in CS was set as 1. The asterisk indicates a significant difference between the CS and CR at the 0.05 level ( $t$ test). “*” indicates a statistically significant difference $(P<0.05)$

\section{Discussion}

The mechanisms underlying insecticide resistance in insects are complex. Changes in protein expression can provide a basis for understanding the potential effects on pest resistance to pesticides (GuiLu and Wen 2018). Proteomics is a useful method which provides insights into mechanisms involved in physiological changes at the protein level (Zhang et al. 2019). Due to its resolution, robustness, and ability to isolate entire, intact proteins, 2-DE has become a classic method for proteomics research (Rabilloud et al. 2010). In this study, eleven differentially abundant protein spots were separated by 2-DE and were successfully identified. Nine proteins were up regulated and two proteins 
were down regulated in our study. Metabolism-related proteins accounted for the majority of the differentiallyexpressed proteins. The results provided evidence that chlorantraniliprole induces proteomic changes in P. xylostella and that metabolism-related proteins play an important role in the DBM's resistance to chlorantraniliprole. This is consistent with transcriptome analysis (Lin et al. 2013).

Target mutations and the enhancement of the metabolic activities of detoxification enzymes are the two primary factors responsible for insecticide resistance in insects (Heckel 2012; Li et al. 2007; Liu et al. 2017). Different detoxification enzymes such as P450, CarE and GSTs have been reported to contribute to resistance ( $\mathrm{Li}$ and $\mathrm{Liu}$ 2017, 2019; Li et al. 2018; Lumjuan et al. 2011; Ullah et al. 2020b; Wang et al. 2013). In this study, five metabolism-

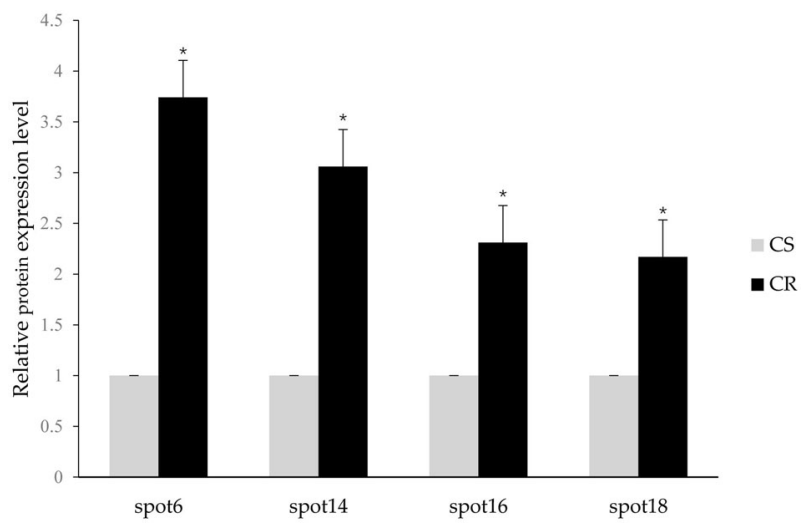

Fig. 4 Expression of four genes at the protein levels between the chlorantraniliprole-sensitive (SS) and resistant (RS) strains of P.xylostella. Spot 6: $\mathrm{Cu} / \mathrm{Zn}$ superoxide dismutase; Spot 14: glutathione S-transferase 4 protein; Spot 16: triosephosphate isomerase; Spot 18: imaginal disk growth factor. CS, susceptible $P$. xylostella strain; CR, chlorantraniliprole resistant DBM strain. The expression level of the protein and mRNA in CS was set as 1. The asterisk indicates a significant difference between the CS and CR at the 0.05 level ( $t$ test). “*” indicates a statistically significant difference $(P<0.05)$ related differential proteins were found, and they accounted for the highest proportion of the differentially-expressed proteins. Among these, PxGST2L belongs to the GSTs family which is a major family of detoxification enzymes involved in phase II metabolism. The insect GSTs play key roles in the metabolism of xenobiotic compounds and can enhance insecticide resistance by binding to insecticide molecules. They are also involved in insecticide detoxification by mediating O-dealkylation and catalyzing dehydrochlorination (Chen et al. 2018; Konanz and Nauen 2004; Kostaropoulos et al. 2001; Lyall 2006; Vontas et al. 2001). The GST activity has been associated with resistance to pesticides in many insects. For example, GSTs play critical roles in chlorpyrifos detoxification in Spodoptera litura Fabricius (Lepidoptera:Noctuidae). Three cytosolic SlGSTs (SlGSTe13, SlGSTt1 and SlGSTz1) and one microsomal Slgst (SIMGST1-1) were induced only in the resistant strain. Eight cytosolic SlGSTs were expressed 1.52-5.15-fold higher in the resistant strain than in the susceptible strain (Zhang et al. 2016). In Locusta migratoria manilensis (Orthoptera:Acridiae), FLmGSTs 3 was reported to be involved in carbaryl detoxification. After silencing the LmGSTs 3 and treating the larvae with carbaryl, the nymph mortalities increased by 38.7\% (Qin et al. 2012). Further, BdGSTe8 played a role in metabolic resistance to malathion in Bactrocera dorsalis (Diptera: Tephritidae). The susceptibility of a malathion-resistant strain recovered after knockdown the BdGSTe8-B, and overexpression of BdGSTe8 enhanced resistance in transgenic Drosophila. $B d G S T e 8-B$ allele was also reported to be involved in the direct metabolism of malathion by metabolic assay ( $\mathrm{Lu}$ et al. 2020). Huang et al. studied the expression characteristics of the Sigma family GSTs under pesticide stress in Chilo suppressalis (Walker) (Lepidoptera:Pyralidae). They found that avermectins and chlorantraniliprole induced a higher expression of the Sigma family GSTs. Their relative
Fig. 5 Functional analysis of $P x G S T 2 L$ by RNAi. (A)

Relative expression of PxGST2L in the third-instar larvae injected with dsPxGST2L or dsGFP. (B) The Glutathione S-transferase activity of third-instar larvae injected with dsPxGST2L or dsGFP. Data represent the mean \pm SD of three biological replicates. The asterisk * in (A) and $(\mathbf{B})$ indicates a statistically significant difference $(P<0.05)$ in gene expression between control and treatment
A

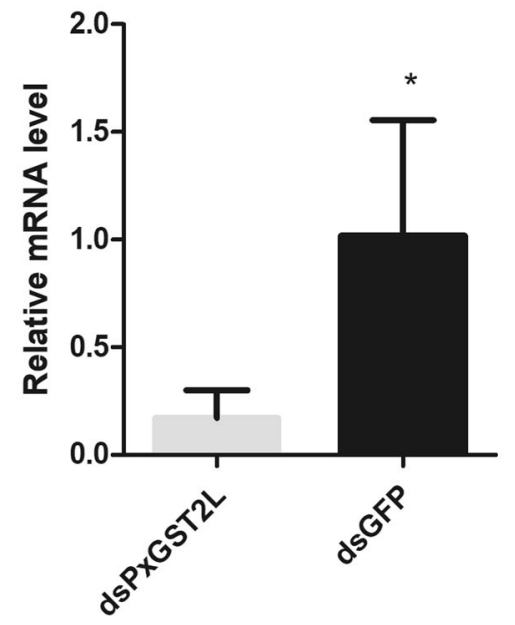

B

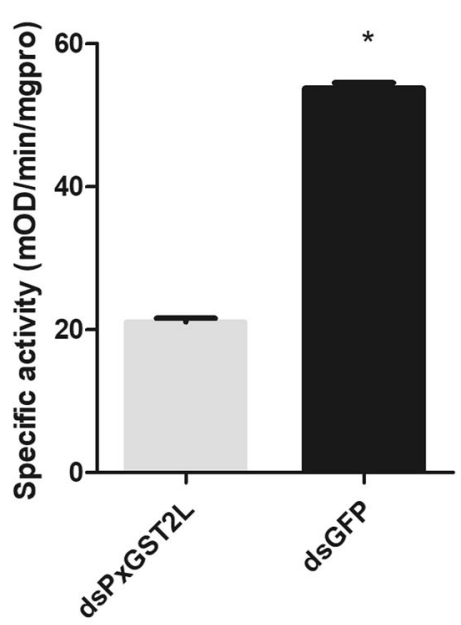


Table 5 Toxicity of chlorantraniliprole against different strains of P.xylostella $\mathrm{L}$.

\begin{tabular}{|c|c|c|c|c|c|}
\hline Control & Regression equation & LC50 (mg/L) & $95 \%$ confidence interval $/ \mathrm{mg} \cdot \mathrm{L}-1$ & $X^{2}(d f)^{a}$ & $\mathrm{RR}^{\mathrm{b}}$ \\
\hline susceptible species & $Y=1.592 x+1.061$ & 0.22 & $0.13-0.36$ & $0.696(3)$ & - \\
\hline dsPxGST2L & $Y=0.900 x-1.860$ & 116.22 & $56.94-206.21$ & $0.479(3)$ & 505 \\
\hline dsGFP & $Y=0.692 x-1.642$ & 236.74 & $118.00-1244.72$ & $0.205(3)$ & 1029 \\
\hline CK & $Y=0.707 x-1.748$ & 296.19 & $150.40-2628.15$ & $0.084(3)$ & 1346 \\
\hline
\end{tabular}

${ }^{\mathrm{a}}$ Chi-square value $\left(\mathrm{X}^{2}\right)$ and degrees of freedom (df)

${ }^{\mathrm{b}} \mathrm{RR}$ (resistance ratio) $=$ the resistant population LC50/ the susceptible population LC50

expression levels were increased 7.1-44.5 times under the inducement of chlorantraniliprole. The results suggested that the Sigma family GSTs plays an important role in resisting the negative effects caused by xenobiotics (Jia et al. 2011). In P. xylostella, the increase in GST activity enhances its resistance to organophosphates, spinosad, pyrethhroids and indoxacarb (Chen and Zhang 2015). Compared with the susceptible population, the activity of GST in the resistant population of DBM to chlorantraniliprole increased significantly. The activity of GST was twice as high as that in the susceptible population. Meanwhile, it was found that the toxicity of chlorantraniliprole to DBM can be synergized by the GSTs specific inhibitor diethy-maleate (DEM). The results indicated that GSTs play potential detoxification roles in the metabolism of DBM to chlorantraniliprole (Chen and Zhang 2015). In this study, the results of 2 - DE showed that PxGST2L was significantly up-regulated in CR. It showed that PxGST2L was closely associated with chlorantraniliprole resistance in DBM.

RNAi has been used to confirm the role of candidate detoxification genes. The genes silencing by RNAi will enhance the role of insecticides, which had been proved by the susceptibility of carbaryl to L. migratoria (Li et al. 2018) and the toxicity of chlorantraniliprole to DBM ( $\mathrm{Li}$ et al. 2018). Also, the toxicity of chlorantraniliprole to DBM was increased by $26.8 \%$ from the silencing of $C Y P 6 B G 1$ by RNAi. Further, the knockdown of GSTe 2 or GSTe7 effectively increased the susceptibility of Aedes aegypti (Diptera:Culicidae) to deltamethrin (Li et al. 2018). The silencing efficiency recorded in this study was more than $76 \%$. After the silencing of the PxGST2L, the activities of GSTs and $\mathrm{LC}_{50}$ of DBM to chlorantraniliprole were significantly decreased. All results provide evidence that $P x G S T 2 L$ are closely related to the resistance of DBM to chlorantraniliprole.

GST can enhance insect's resistance by directly metabolizing or sequestrating chemicals or providing protection against oxidative stress induced by insecticide exposure. However, it was not clear in this study which mechanism caused the increased resistance to chlorantraniliprole in the DBM. It has been reported that the P450 gene is also a factor in the metabolism of DBM to chlorantraniliprole, and here GST is also a factor. But the relationship between the two metabolic enzymes needs to be further clarified. Further clarifying the regulatory metabolic pathway of GST will be helpful to the development of new drugs and the protection of diamides.

\section{Conclusions}

In this paper, the highest proportion of metabolic proteins was found by differential proteomics analysis. The PxGST2L is partly responsible for chlorantraniliprole insecticide resistance in DBM. These results provide new insights into the mechanisms of resistance to chlorantraniliprole insecticides in insect pests.

\section{Data availability}

The authors declare the availability of data and material.

Funding This research was supported by National Natural Science Foundation of China (Grant No:31701819), the National Key Project of Research and Development Plan (Grant No: 2018YFD0201200), the National Key Project of Research and Development Plan (Grant No: 2017YFD0201200), Discipline team building projects of Guangdong Academy of Agricultural Sciences in the 14th Five-Year Period (202105TD) and Natural Science Foundation of Guangdong Province (2021A1515012385).

Author contributions Data curation, XW; resources and writing-original draft, FY; review \& editing, QL, ZL, and MZS.

\section{Compliance with ethical standards}

Conflict of interest The authors declare no competing interests.

Publisher's note Springer Nature remains neutral with regard to jurisdictional claims in published maps and institutional affiliations.

Open Access This article is licensed under a Creative Commons Attribution 4.0 International License, which permits use, sharing, adaptation, distribution and reproduction in any medium or format, as long as you give appropriate credit to the original author(s) and the source, provide a link to the Creative Commons license, and indicate if 
changes were made. The images or other third party material in this article are included in the article's Creative Commons license, unless indicated otherwise in a credit line to the material. If material is not included in the article's Creative Commons license and your intended use is not permitted by statutory regulation or exceeds the permitted use, you will need to obtain permission directly from the copyright holder. To view a copy of this license, visit http://creativecommons. org/licenses/by/4.0/.

\section{References}

Arruda LS, Rodrigues A, Bermudez N, Ribeiro L, Siqueira H (2020) Field resistance of Plutella xylostella (Lepidoptera: Plutellidae) to lufenuron: inheritance and lack of cross-resistance to methoxyfenozide. Crop Prot 136:105237

Bu Q et al. (2012) Proteomic analysis of the nucleus accumbens in rhesus monkeys of morphine dependence and withdrawal intervention. J Proteomics 75:1330-1342

Charleston DS, Kfir R, Dicke M, Vet LEM (2005) Impact of botanical pesticides derived from Melia azedarach and Azadirachta indica on the biology of two parasitoid species of the diamondback moth. Biol Control 33:131-142

Chen S, Lu M, Zhang N, Zou X, Mo M, Zheng S (2018) Nuclear factor erythroid-derived 2-related factor 2 activates glutathione $S$ transferase expression in the midgut of Spodoptera litura (Lepidoptera: Noctuidae) in response to phytochemicals and insecticides. Insect Mol Biol 27:522-532. https://doi.org/10.1111/imb. 12391

Chen X, Zhang Y (2015) Identification and characterisation of multiple glutathione S-transferase genes from the diamondback moth, Plutella xylostella. Pest Manag Sci 71:592-600. https://doi.org/ $10.1002 /$ ps.3884

Cordova D et al. (2006) Anthranilic diamides: a new class of insecticides with a novel mode of action, ryanodine receptor activation. Pestic Biochem Physiol 84:196-214

Desneux N, Decourtye A, Delpuech JM (2007) The sublethal effects of pesticides on beneficial arthropods. Annu Rev Entomol 52:81-106

Etebari K, Palfreyman RW, Schlipalius D, Nielsen LK, Glatz RV, Asgari S (2011) Deep sequencing-based transcriptome analysis of Plutella xylostella larvae parasitized by Diadegma semiclausum. Bmc Genomics 12:446. https://doi.org/10.1186/1471-2164-12-446

Furlong MJ, Wright DJ, Dosdall LM (2013) Diamondback moth ecology and management: problems, progress, and prospects. Annu Rev Entomol 58:517-541. https://doi.org/10.1146/annurevento-120811-153605

Guedes RNC et al. (2019) Insecticide resistance in the tomato pinworm Tuta absoluta: patterns, spread, mechanisms, management and outlook. J Pest Sci 92:1329-1342. https://doi.org/10.1007/ s10340-019-01086-9

GuiLu Z, Wen J (2018) Protein-protein interaction network analysis of insecticide resistance molecular mechanism in Drosophila melanogaster. Arch Insect Biochem 100:e2153

Gul H, Ullah F, Biondi A, Desneux N, Song D (2019) Resistance against clothianidin and associated fitness costs in the chive maggot, Bradysia odoriphaga. Entomol Gen 39:81-92

Guo L, Wang Y, Zhou X, Li Z, Liu S, Pei L, Gao X (2014) Functional analysis of a point mutation in the ryanodine receptor of Plutella xylostella (L.) associated with resistance to chlorantraniliprole. Pest Manag Sci 70:1083-1089

He F et al. (2019) Compatibility of chlorantraniliprole with the generalist predator Coccinella septempunctata L. (Coleoptera: Coccinellidae) based toxicity, life-cycle development and population parameters in laboratory microcosms. Chemosphere 225:182-190
He W et al. (2012) Developmental and insecticide-resistant insights from the de novo assembled transcriptome of the diamondback moth, Plutella xylostella. Genomics 99:169-177

Heckel D (2012) Insecticide resistance after silent spring. Science (New York, N.Y.) 337:1612-1614. https://doi.org/10.1126/ science. 1226994

Ingham VA, Wagstaff S, Ranson H (2018) Transcriptomic metasignatures identified in Anopheles gambiae populations reveal previously undetected insecticide resistance mechanisms. Nat Commun 9:5282. https://doi.org/10.1038/s41467-018-07615-x

Jia H, Shunfan W, Gongyin Y (2011) Molecular Characterization of the Sigma Class Gutathione S-Transferase From Chilo suppressalis and Expression Analysis Upon Bacterial and Insecticidal Challenge. J Econ Entomol 104:2046-2053

Jin T, Zeng L, Lu Y, Xu Y, Liang G (2010) Identification of resistance-responsive proteins in larvae of Bactrocera dorsalis (Hendel), for pyrethroid toxicity by a proteomic approach. Pestic Biochem Physiol 96:1-7

Jing W et al. (2021) Insecticide Resistance Monitoring of the Diamondback Moth (Lepidoptera: Plutellidae) Populations in China. J Econ Entomol toab027, https://doi.org/10.1093/jee/toab027

Konanz S, Nauen R (2004) Purification and partial characterization of a glutathione S-transferase from the two-spotted spider mite, Tetranychus urticae. Pestic Biochem Physiol 79:49-57

Kostaropoulos I, Papadopoulos AI, Metaxakis A, Boukouvala E, Papadopoulou-Mourkidou E (2001) Glutathione S-transferase in the defence against pyrethroids in insects. Insect Biochem Molec 31:313-319

Lahm GP et al. (2005) Insecticidal anthranilic diamides: a new class of potent ryanodine receptor activators. Bioorg Med Chem Lett 15:4898-4906. https://doi.org/10.1016/j.bmcl.2005.08.034

Lahm GP et al. (2007) Rynaxypyr ${ }^{\mathrm{TM}}$ : a new insecticidal anthranilic diamide that acts as a potent and selective ryanodine receptor activator. Bioorg Med Chem Lett 17:6274-6279. https://doi.org/ 10.1016/j.bmcl.2007.09.012

Li J, Jin M, Wang N, Yu Q, Xue C (2020) Combined transcriptomic and proteomic analysis of flubendiamide resistance in Plutella xylostella, Entomol Res 50:483-492. https://doi.org/10.1111/ 1748-5967.12466

Li T, Liu N (2017) Regulation of P450-mediated permethrin resistance in Culex quinquefasciatus by the GPCR/Gas/AC/cAMP/PKA signaling cascade. Biochem Biophys Rep 12:12-19. https://doi. org/10.1016/j.bbrep.2017.08.010

Li T, Liu N (2019) Role of the G-protein-coupled receptor signaling pathway in insecticide resistance. Int J Mol Sci 20:4300

Li X, Li R, Zhu B, Gao X, Liang P (2018) Overexpression of cytochrome P450 CYP6BG1 may contribute to chlorantraniliprole resistance in Plutella xylostella (L.). Pest Manag Sci 74:1386-1393. https://doi.org/10.1002/ps.4816

Li X, Schuler MA, Berenbaum MR (2007) Molecular mechanisms of metabolic resistance to synthetic and natural xenobiotics. Annu Rev Entomol 52:231-253

Li Z, Feng X, Liu S, You M, Furlong MJ (2016) Biology, ecology, and management of the diamondback moth in China. Annu Rev Entomol 61:277-296

Lin Q et al. (2013) Transcriptome analysis of chlorantraniliprole resistance development in the diamondback moth Plutella xylostella. Plos ONE 8:e72314

Lu X, Xu L, Meng L, Wang L, Niu J, Wang J (2020) Divergent molecular evolution in glutathione S-transferase conferring malathion resistance in the oriental fruit fly, Bactrocera dorsalis (Hendel). Chemosphere 242:125203. https://doi.org/10.1016/j. chemosphere.2019.125203

Lumjuan $\mathrm{N}$ et al. (2011) The role of the Aedes aegypti Epsilon glutathione transferases in conferring resistance to DDT and pyrethroid insecticides. Insect Biochem Mol Biol 41:203-209 
Lyall MS (2006) Profiling markers of prognosis in colorectal cancer. Clin Cancer Res 12:1184-1191

Liu X, Tang Q, Li Y, Campos MR, Liang P, Gao X (2017) Widespread resistance of the aphid Myzus persicae to pirimicarb across China, and insights on ace 2 mutation frequency in this species. Entomol Gen 36:285-299

Li X, Zhu B, Gao X, Liang P (2016) Over-expression of UDPglycosyltransferase gene UGT2B17 is involved in chlorantraniliprole resistance in Plutella xylostella (L.). Pest Manag Sci 73:1402-1409

Oliveira RL, Gontijo PC, Samia RR, Carvalho GA (2019) Long-term effects of chlorantraniliprole reduced risk insecticide applied as seed treatment on lady beetle Harmonia axyridis (Coleoptera: Coccinellidae). Chemosphere 219:678-683

Parsaeyan E, Saber M, Safavi SA, Poorjavad N, Biondi A (2020) Side effects of chlorantraniliprole, phosalone and spinosad on the egg parasitoid, Trichogramma brassicae, Ecotoxicology 29:1052-1061

Pu X, Yang Y, Wu S, Wu Y (2010) Characterisation of abamectin resistance in a field-evolved multiresistant population of Plutella xylostella. Pest Manag Sci 66:371-378. https://doi.org/10.1002/ ps. 1885

Qin $\mathrm{G}$ et al. (2012) Heterologous expression and characterization of a sigma glutathione S-transferase involved in carbaryl detoxification from oriental migratory locust, Locusta migratoria manilensis (Meyen). J Insect Physiol 58:220-227. https://doi.org/10.1016/j. jinsphys.2011.10.011

Rabilloud T, Chevallet M, Luche S, Lelong C (2010) Twodimensional gel electrophoresis in proteomics: past, present and future. J Proteomics 73:2064-2077. https://doi.org/10.1016/j. jprot.2010.05.016

Ribeiro LMS, Wanderley-Teixeira V, Ferreira HN, C. TÁA, Siqueira HAA (2014) Fitness costs associated with field-evolved resistance to chlorantraniliprole in Plutella xylostella (Lepidoptera: Plutellidae). B Entomol Res 104:88-96

Sarfraz M, Dosdall LM, Keddie BA (2006) Diamondback moth-host plant interactions: implications for pest management. Crop Prot 25:625-639

Takeda T, Nakamatsu Y, Tanaka T (2006) Parasitization by Cotesia plutellae enhances detoxifying enzyme activity in Plutella xylostella. Pestic Biochem Phys 86:15-22. https://doi.org/10. 1016/j.pestbp.2005.11.012

Ullah F, Gul H, Desneux N, Gao X, Song D (2019a) Imidaclopridinduced hormesis effects on demographic traits of the melon aphid, Aphis gossypii. Entomol Gen 39:325-337

Ullah F, Gul H, Desneux N, Qu Y, Song D (2019b) Acetamipridinduced hormetic effects and vitellogenin gene $(\mathrm{Vg})$ expression in the melon aphid, Aphis gossypii. Entomol Gen 39:259-270

Ullah F, Gul H, Desneux N, Tariq K, Song D (2019c) Clothianidininduced sublethal effects and expression changes of vitellogenin and ecdysone receptors genes in the melon aphid, Aphis gossypii. Entomol Gen 39:137-149

Ullah F, Gul H, Tariq K, Desneux N, Gao X, Song D (2020a) Fitness costs in clothianidin-resistant population of the melon aphid, Aphis gossypii. Plos ONE 15:e238707. https://doi.org/10.1371/ journal.pone. 0238707
Ullah F, Gul H, Tariq K, Desneux N, Song D (2020b) Functional analysis of cytochrome P450 genes linked with acetamiprid resistance in melon aphid Aphis gossypii. Pestic Biochem Phys 170:104687

Vontas JG, Small GJ, Hemingway J (2001) Glutathione S-transferases as antioxidant defence agents confer pyrethroid resistance in Nilaparvata lugens. Biochem J 357:65-72

Wang X, Cao X, Jiang D, Yang Y, Wu Y (2020) CRISPR/Cas9 mediated ryanodine receptor I4790M knockin confers unequal resistance to diamides in Plutella xylostella. Insect Biochem Molec 125:103453. https://doi.org/10.1016/j.ibmb.2020.103453

Wang X, Khakame SK, Ye C, Yang Y, Wu Y (2013) Characterisation of field-evolved resistance to chlorantraniliprole in the diamondback moth, Plutella xylostella, from China. Pest Manag Sci 69:661-665

Wang X, Li X, Shen A, Wu Y (2010) Baseline susceptibility of the diamondback moth (Lepidoptera: Plutellidae) to chlorantraniliprole in China. J Econ Entomol 103:843-848

Wang X et al. (2019) Long-term monitoring and characterization of resistance to chlorfenapyr in Plutella xylostella (Lepidoptera: Plutellidae) from China Pest Manag Sci 75:591-597. https://doi. org/10.1002/ps.5222

Wang X, Wu Y (2012) High levels of resistance to chlorantraniliprole evolved in field populations of plutella xylostella. J Econ Entomol 105:1019-1023. https://doi.org/10.1603/ec12059

Williams JR, Swale DR, Anderson TD (2020). Comparative effects of technical-grade and formulated chlorantraniliprole to the survivorship and locomotor activity of the honey bee, Apis mellifera (L.). Pest management science 76:2582-2588

Xu J, Wang Z, Wang Y, Ma H, Zhou X (2019) ABCC2 participates in the resistance of Plutella xylostella to chemical insecticides. Pestic Biochem Phys 162:52-59

Yin F, Lin Q, Feng X, Chen H, Li Z, Hu Z (2017) Analysis of differentially expressed proteins between the spinetoramsusceptible and -resistant strains of Plutella xylostella (L.). J Asia-Pac Entomol 20:119-124. https://doi.org/10.1016/j.aspen. 2016.11.003

Zhang T, Yuan Q, Gu Z (2019) Advances of proteomics technologies for multidrug-resistant mechanisms. Future Med Chem 11:2573-2593

Zhang N, Liu J, Chen SA, Huang LU, Zheng SH (2016) Expression profiles of glutathione S-transferase superfamily in Spodoptera litura tolerated to sublethal doses of chlorpyrifos. Insect Sci 23:675-687

Zhang Y, Guo L, Atlihan R, Chi H, Chu D (2019) Demographic analysis of progeny fitness and timing of resurgence of Laodelphax striatellus after insecticides exposure. Entomol Gen 39 (3-4): 221-230

Zhao JZ, Collins HL, Li YX, Mau RFL, Shelton AM (2006) Monitoring of diamondback moth (Lepidoptera: Plutellidae) resistance to Spinosad, Indoxacarb, and Emamectin Benzoate. J Econ Entomol 99:176-181

Zhou J et al. (2020) Reduced expression of the P-glycoprotein gene PXABCB1 is linked to resistance to Bacillus thuringiensis Cry1Ac toxin in Plutella xylostella (L.). Pest Manag Sci 76:712-720. https://doi.org/10.1002/ps.5569 